\section{Liquid nitrogen storage of haemoglobin variants}

R. G. HUNTSMAN, B. A. L. HURN, J. LIDDELL, H. LEHMANN ${ }^{1}$, AND P. K. SUKUMARAN ${ }^{1}$ From the Memorial Hospital, Peterborough, The Royal Free Hospital, London, the Radcliffe Infirmary, Oxford, and St. Bartholomew's Hospital, London

The preservation of abnormal haemoglobin solutions for reference purposes is difficult. The majority when stored for a few weeks at $-20^{\circ} \mathrm{C}$. shows on subsequent electrophoresis a variable degree of blurring of the previously distinct bands. This deterioration is progressive. The most unstable of them is haemoglobin $\mathrm{H}$ which rapidly denatures on freezing. When a solution of haemoglobin $\mathbf{H}$

1 M.R.C. abnormal hasmoglobin research unit

Received for publication 26 April 1963. is thawed immediately after freezing a precipitate of denatured protein can be seen in the solution.

We have recently been investigating the storage of human red cells in liquid nitrogen for serological purposes (Huntsman, Hurn, Ikin, Lehmann, and Liddell, 1962). We thought that this technique might be useful for the preservation of haemoglobin as well as for that of the red cell agglutinins. We have therefore stored in liquid nitrogen, cells and haemoglobin solutions containing haemoglobins $\mathrm{A}+\mathrm{S}, \mathrm{A}+\mathrm{H}$ ( + trace of Bart's), $A+G_{a \text { Norfolk }}, A+D_{\beta \text { Punjab }}$ as well as normal samples containing only haemoglobin $A$ and haemoglobin $A_{2}$. All these samples were stored for six months, both in a liquid nitrogen refrigerator at $-196^{\circ} \mathrm{C}$. and in the conventional deep freeze cabinet at $-20^{\circ} \mathrm{C}$. The cells were frozen both as packed red cells and as whole blood containing $13 \%$ sucrose.

The haemoglobin $\mathrm{A}+\mathrm{H}$ solution which had been stored at $-196^{\circ} \mathrm{C}$. showed no precipitation while the subsequent electrophoresis (shown in the figures) was satisfactory. The red cells containing haemoglobin $\mathbf{H}$ after similar storage showed no inclusion bodies after

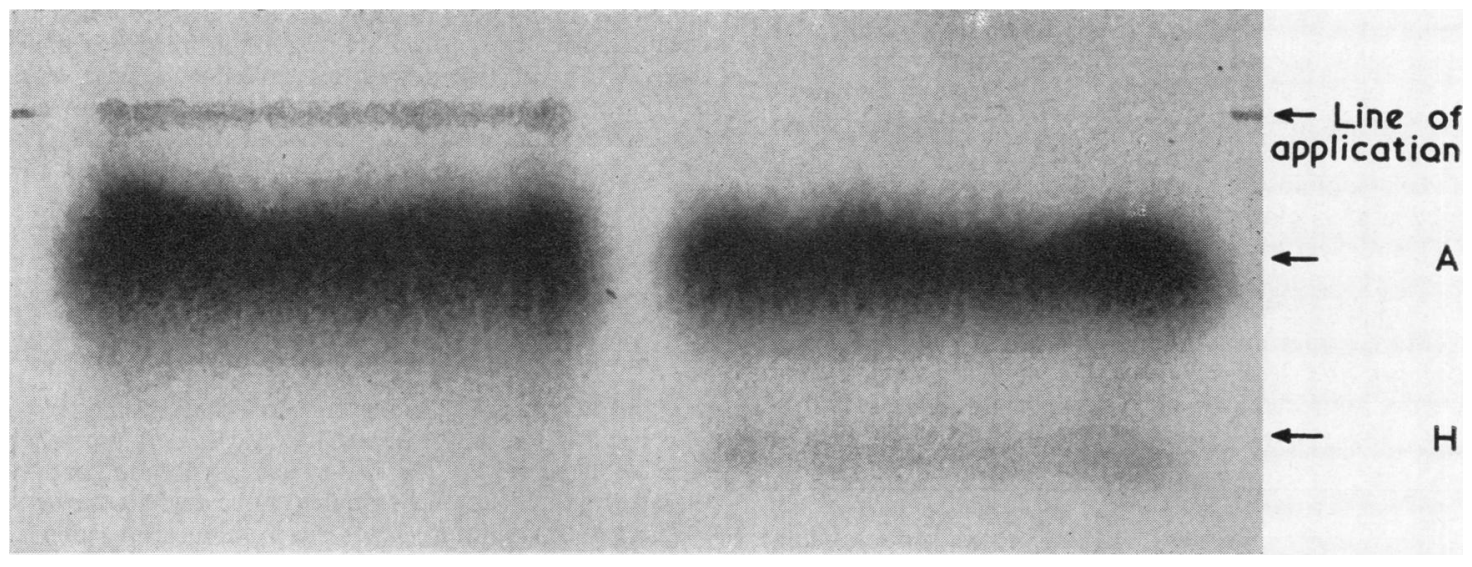

FIG. 1. Tris buffer electrophoresis (paper, pH 8.9) of two specimens of haemoglobin $A+H(+$ trace of Bart's). LEFT Haemoglobin solution stored for one month in refrigerator. Almost no $H$ is present and denatured haemoglobin is precipitated at the line of application. RIGHT Haemoglobin solution stored for one month in liquid nitrogen. There is no denatured haemoglobin at the line of application and haemoglobin $H$ is preserved.

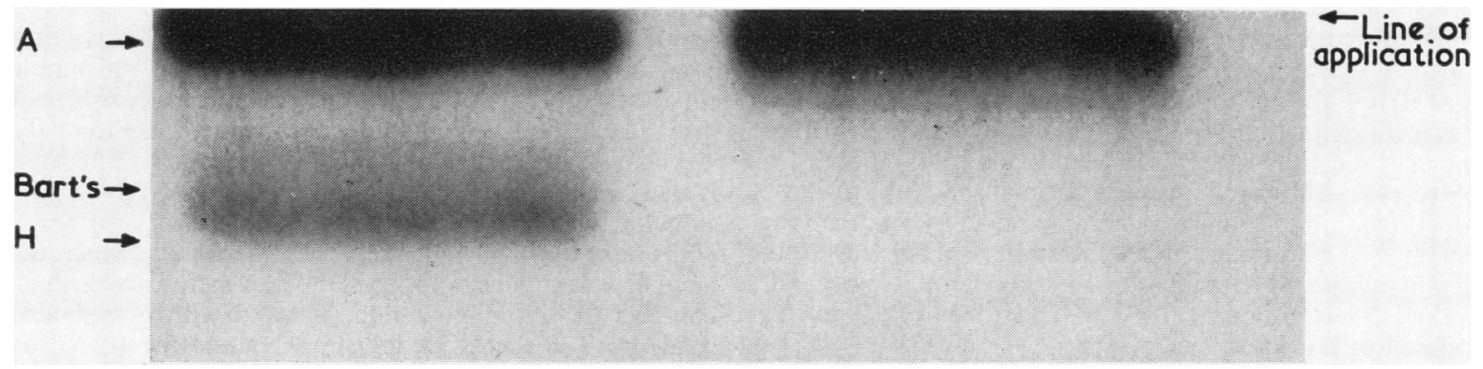

FIG. 2. Starch gel electrophoresis ( $p H$ 7.7) of the same specimens as shown in Figure 1. LEFT Stored in liquid nitrogen; the small amount of haemoglobin Bart's is seen moving behind the haemoglobin $H$ band. RIGHT Stored in the refrigerator. 


\section{A simple control system for $\mathrm{CO}_{2}$ incubators}

\section{B. M. WRIGHT From the National Institute for Medical Research, Mill Hill, London}

Incubators in which a concentration of $3-4 \% \mathrm{CO}_{2}$ in the atmosphere is maintained are commonly used in virological work, but no entirely satisfactory system seems to have been developed for keeping the concentration within the required limits for long periods. The obvious solution, a device which measures the concentration and feeds in $\mathrm{CO}_{2}$ as required, is relatively complicated and expensive and requires a certain amount of skilled maintenance which is often not available. Another solution which is commonly employed is to supply a flow of $\mathrm{CO}_{2} /$ air mixture of the required concentration to flush out the incubator. This has the disadvantage that such mixtures are relatively expensive to prepare, and if the $\mathrm{CO}_{2}$ concentration in the incubator is to be brought rapidly to the required level every time it has fallen as a result of the door being opened, a large volume of mixture is required.

An operational analysis of the behaviour and use of such an incubator showed that in practice only a very simple system should be necessary.

To maintain the desired $\mathrm{CO}_{2}$ concentration when the incubator is closed required only a slow steady flow of $\mathrm{CO}_{2}$ sufficient to make up losses due to leakage, which, in a well-sealed incubator should be so small as to require a flow of only a few millilitres of $\mathrm{CO}_{2}$ per minute.

More important, this flow should be quite constant, because the leakage from the incubator should not change appreciably from day to day; if it does, it is better

Received for publication 30 April 1963.

Liquid nitrogen storage of haemoglobin variants-cont.

vital staining. These inclusion bodies which arise from the denaturation of haemoglobin $\mathrm{H}$, however, developed after two hours' incubation with cresyl blue as would normally occur with fresh cells. Red cells from a carrier of the sickle-cell trait retained the sickling phenomenon after freezing in liquid nitrogen and subsequent thawing. The stored solutions of haemoglobins $A+G, A+D$, and $A+G$ respectively had identical electrophoretic properties to fresh solutions. Electrophoresis was also performed on haemoglobin solutions prepared from normal red cells which had been stored at $-196^{\circ} \mathrm{C}$. for two years. The results were indistinguishable from those obtained with fresh solutions, and in particular the small $A_{2}$ component was as clearly visible as with freshly prepared haemolysates. This technique appears of value for the storage of human haemoglobins for references purposes.

\section{REFERENCE}

Huntsman, R. G., Hurn, B. A. L., Ikin, E. W., Lehmann, H., and Liddell, J. (1962). Brit. med. J., 2, 1508. to improve the sealing rather than to try to follow changes by adjusting the $\mathrm{CO}_{2}$ feed. Since the leakage $\mathrm{of}$ $\mathrm{CO}_{2}$ takes place by diffusion it is proportional to the corcentration which will not therefore build up excessively if the $\mathrm{CO}_{2}$ feed rate is greater than required. In ot ger words, it is an inherently stable system for which colltinuous automatic control is unnecessary.

Similarly, replacement of the loss of $\mathrm{CO}_{2}$ resulting from opening the incubator does not require $\mathrm{CO}_{2}$ concentention to be measured, because in practice it is found that the $\mathrm{CO}_{2}$ concentration falls almost to zero every time door is opened. Restoration of the $\mathrm{CO}_{2}$ concentration $\overrightarrow{\mathrm{s}}$ therefore simply a matter of putting in the correct volufye of $\mathrm{CO}_{2}$, calculated from the volume of the incubator and the concentration required.

As a result of this operational analysis a system $\vec{g} f$ $\mathrm{CO}_{2}$ control has been developed over the past two years which is simple to make and use, and yet gives quite saitiofactory control of the $\mathrm{CO}_{2}$ concentration at all times.

The principle of the system is as follows:

A slow steady flow of $\mathrm{CO}_{2}$ into the incubator is maintained at a rate which is found by experiment to keep the concentration within the required limits, so long as incubator is closed. To replace the $\mathrm{CO}_{2}$ lost when door has been opened a flow of $200 \mathrm{ml}$./minute is maintained for a variable period, controlled by a time valuec, the period required being calculated from the volume the incubator and the $\mathrm{CO}_{2}$ concentration desired. The time valve is operated manually by the user each time opens and shuts the incubator.

The control system consists of the following compnents, which may be arranged in relation to the incubator, as shown in the Figure.

\section{THE CONTROL SYSTEM}

STAND FOR THE GAS CYLINDER AND OTHER COMPONEN The stand is important because $\mathrm{CO}_{2}$ cylinders are otherwise liable to be laid down in such a position that ffre liquefied gas enters the reducing valve and damages?at. Neglect of this point is one of the commonest reasons $\bar{E}$. failure to maintain a steady flow of gas. The base of the stand serves as a convenient attachment for the tige valve, so that it can be operated with one hand.

$\mathrm{CO}_{2}$ CYLINDER FITTED WITH A PRESSURE-REDUCING VAL퓨E PRESSURE GAUGE, AND NEEDLE VALVE A cylinder of th. ( $3.19 \mathrm{~kg}$.) capacity is usually a convenient size and lașts about three weeks. The pressure in the cylinder is faindy constant at about 60 atmospheres, so a cheap and simple single-stage valve will reduce the pressure with sufficiej precision. The pressure gauge is of value, in spite of the fact that the cylinder pressure is nearly constant, because it gives warning when the liquid is exhausted. With a 7 b. cylinder the remaining gas will usually last for 24 hoffs with normal use, and longer at weekends when incubator is not being opened. The needle valve, which controls the rapid flow rate, is fitted with a shrouded screw head so that it its adjustment cannot be altered $\$$ y casual visitors.

TIME-CONTROLLED GAS VALVE WITH FINE ADJUSTMERT NEEDLE VALVE The time-controlled valve is made frem 